\title{
Prevalence of Stunting and Thinness Among Adolescent Girls Belonging to the Rajbanshi Population of West Bengal, India
}

\author{
Roy $\mathbf{S}^{1}$, Barman $\mathbf{S}^{2}$, Mondal $\mathrm{N}^{3}$, Sen $\mathrm{J}^{4}$
}

${ }^{1}$ Susmita Roy, M.Sc. UGC-Rajiv Gandhi Fellow, Department of Anthropology, ${ }^{2}$ Sweeta Barman, M.Sc. Ex- Post Graduate Student, Department of Anthropology, University of North Bengal, ${ }^{3}$ Nitish Mondal, M.Sc, Ph.D. Assistant Professor, Department of Anthropology, Assam University (Diphu Campus), Karbi Anglong, Assam, India, 'Jaydip Sen, M.Sc, Ph.D. Professor, Department of Anthropology, University of North Bengal, Darjeeling, West Bengal, India.

\section{Address for correspondence: \\ Dr. Nitish Mondal (PhD) \\ Department of Anthropology \\ Assam University (Diphu Campus) \\ Diphu, Karbi Anglong, Assam, India \\ Tel No; +91-9613712613 \\ E-mail: nitish_slg@rediffmail.com}

Acknowledgements: The authors acknowledge the help and co-operation of the schools' authorities and participants.

Funding: University Grants Commission, India Conflict of Interest: Authors have no conflict of interest

Permission from IRB: Yes

Ethical dilemmas faced during study: No

\section{How to cite}

Roy S, Barman S, Mondal N, Sen J. Prevalence of Stunting and Thinness Among Adolescent Girls Belonging to the Rajbanshi Population of West Bengal, India. J Nepal Paediatr Soc 2016;36(2):147-155.

doi: http://dx.doi.org/10.3126/jnps.v36i2.14535

This work is licensed under a Creative Commons Attribution 3.0 License.

\begin{abstract}
Introduction: In India majority of the individuals remain undernourished. The primary causes of undernutrition are its large population, socio-economic differences and inadequate access to health facilities. Assessment of nutritional status among adolescents is very important as they are the future parents and constitute a potentially vulnerable segment of the population. The present school-based cross-sectional study evaluates the prevalence of stunting and thinness among adolescent girls from North Bengal. Materials and Methods: The present study was carried out among 500 Rajbanshi adolescent girls aged 9 to 18 years and residing in the districts of Darjeeling and Jalpaiguri in West Bengal, India. Anthropometric measurements of height and weight were recorded and body mass index (BMI) calculated. The prevalence of undernutrition was assessed using recommended anthropometric indices of stunting (low height-for-age) and thinness (low BMI-for-age), along with a comparison with the WHO reference population. Results: The overall prevalence of stunting and thinness was observed to be $39.60 \%$ and $26.00 \%$ respectively. The prevalence of age-specific stunting was higher and lower among girls aged 17 years $(70.21 \%)$ and 10 years $(24.00 \%)$, respectively. The age-specific prevalence of thinness was observed to be higher among those aged 10 years $(66.00 \%)$ and lower among those aged 17 years (8.51\%). Conclusion: There is a need for appropriate nutritional intervention programmes to address their nutritional needs. The results of the present study will also help policy makers to formulate various developmental and health care programmes.
\end{abstract}

Key words: Adolescence, Rajbanshi, Anthropometry, Stunting, Undernutrition, India.

\section{Introduction}

U ndernutrition is one of the principal causes of the ill-health condition and premature mortality and morbidity among children and adolescents of many of the developing countries. In India, given its large population size and widespread poverty, a majority of the individuals are undernourished and under privileged ${ }^{1,2,3}$. The period of adolescence ( 9 years to 18 years) is a transition period between 
childhood and adulthood. The exceptional rapid growth during this stage is characterized by enormous individual variations that pose difficulty in defining normality ${ }^{4}$. The nutritional status of adolescent girls, who are the future mothers, bears special importance as they contribute significantly to the overall nutritional status and health of the concerned population or community,6,7,8,9,10. As a group, they are a potentially nutritionally vulnerable one in view of rapid growth and maturation of this period which demands extra nutrients and energy-rich foods ${ }^{8}$. Inadequate diet and unfavourable environmental and socio-economic conditions can adversely affect the physical growth and nutritional status of this group. It may further be associated with many concurrent and future adverse health outcomes, including poor reproductive outcome in girls perpetuating the vicious cycle of malnutrition ${ }^{5,6,10}$.

Currently, it is estimated that adolescents contribute to 1.20 billion of the global population and comprises one of the largest cohorts (243 million) of the Indian population ${ }^{7}$. It is only recently that some efforts have been made to include adolescents as beneficiaries in some of the countrywide health care and nutritional intervention programmes ${ }^{2,10}$.

Anthropometry is a widely used, inexpensive and non-invasive technique available to researchers for the assessment of the body composition and nutritional status among children and adults ${ }^{11-15}$. For the assessing nutritional status of adolescents, the World Health Organisation (WHO) has recommended the use of low height-for-age (stunting) and lowBMl-for-age (thinness) 4,16 with the former indicating chronic undernutrition and the later indicating acute undernutrition ${ }^{4,8,10}$. The prevalence stunting is also recognized to be manifested due to prolonged food deprivation or illness ${ }^{4}$. A number of studies from India have reported that the prevalence of undernutrition poses a major nutritional threat to adolescents $s^{5,8,10,17-29}$. Population investigation studies have also continuously reported that girls are generally shown to exhibit greater nutritional vulnerability than boys ${ }^{8,10}$. Studies have also confirmed that undernutrition among young women of childbearing age is a risk factor for adverse pregnancy outcomes, such as intrauterine growth-restricted or low birth weight infants $\mathrm{s}^{4,6,28,30}$.

The northern part of the state of West Bengal, India is popularly known as North Bengal and comprises of seven districts. It is the home to a number of indigenous populations like the Toto, Rabha, Rajbanshi, Dhimal and Lepcha. Given the region's general backwardness, these populations remain very vulnerable to undernutrition. However, studies are relatively less on the prevalence of undernutrition among individuals belonging to these populations..$^{9,10,31-35}$

Given the above, the present study was conducted to assess the prevalence of stunting and thinness among adolescent girls belonging to the indigenous Rajbanshi population of the region. It is surmised that the results of the present study will be helpful to the policy makers, government and non-government agencies in the formulation of appropriate nutritional intervention strategies in the population.

\section{Materials and Methods}

The present cross-sectional study was carried out among 500 adolescent school-going girls (aged 9 to 18 years) belonging to the Rajbanshi population and residing in North Bengal. All the girls selected for the present study belonged to the Rajbanshi population, which is the most widely distributed indigenous population in North Bengal. According to the National Census of 2001, they constitute the second largest number of Scheduled Caste population in the state of West Bengal (18.40\% and nearly 3.4 million).

A total of four schools located in the districts of Darjeeling and Jalpaiguri in West Bengal, India was covered in the course of the present study. The schools were selected based on the two following criteria:

a) A substantial number of students belonged to the Rajbanshi population.

b) The total student strengths were almost identical.

The girls were selected using a stratified random sampling method. Initially, all the girls belonging to the age group of 9 years to 18 years were identified. Their ages were determined from the school records and verified from the birth certificates issued by the government. Those belonging to the Rajbanshi population were then singled out with their ethnicity being verified from the school records. A total of 545 apparently healthy adolescent Rajbanshi girls were approached to participate in the present study. Of these 545 girls, 45 of them declined to participate in the same. The overall participation rate of the study was, therefore, $91.74 \%$. All the selected girls were free from any physical deformities and were not suffering from any diseases during the time of the study. A modified version of the socio-economic scale of Kuppuswamy ${ }^{36}$ was utilized, so as to ascertain socio-economic status (SES) of the girls. 
Anthropometric measurements of height and weight were taken following standard methods ${ }^{37}$. Height was recorded using an anthropometer rod to the nearest $0.10 \mathrm{~cm}$. The girls were made to stand without footwear with the heels, buttocks, shoulders and occiput touching the anthropometer rod and the hands hanging from the sides. The head was held comfortably upright with the top of the head, making firm contact with the horizontal head piece. Weight of the girls wearing minimum clothing and with bare feet were recorded using a portable weighing machine nearest to $100 \mathrm{gm}$.

The intra-observer and inter-observer technical errors of the measurements (TEM) was calculated following the procedure ${ }^{38}$. Height was recorded from 50 girls other than those selected for the study by two of the authors (SB and JS). The TEM was calculated using the following equation:

$T E M=\sqrt{ }\left(\Sigma D^{2} / 2 N\right), \quad D=$ difference between the measurements, $\mathrm{N}=$ number of individuals.

The co-efficient of reliability $(R)$ was subsequently calculated from TEM using the following equation:

$\mathrm{R}=\left\{1-(\mathrm{TEM})^{2} / \mathrm{SD}^{2}\right\}, \mathrm{SD}=$ standard deviation of the measurements.

Very high values of $R(>0.965)$ were obtained for both inter-and intra-observer measurements. These values were within the cut-off level of 0.95 as suggested ${ }^{38}$. Hence, the measurements recorded by both SB and JS were considered to be reliable and reproducible. All the measurements in the course of the present study were subsequently recorded by one of the authors (SB).

Assessment of nutritional status: Recommended anthropometric parameters and indices of the $\mathrm{WHO}$ have been used to assess nutritional status ${ }^{4}$. The assessment was based on the two conventional indices of height-for-age (stunting) and BMI-for-age (thinness). Height-for-age below the $3^{\text {rd }}$ percentile of the National Centre of Health Statistics (NCHS) reference value was classified as stunting. The thinness (low BMI-forage) was used following the WHO recommended agespecific cut-off points of BMI as based on the Nutritional Health and Nutrition Examination Survey (NHANES) reference value where the $\mathrm{BMI}$-for-age below the $5^{\text {th }}$ percentile of NHANES value was classified as thinness or chronic energy deficiency (CED) ${ }^{4}$.

Statistical analysis: The data was statistically analyzed using statistical constant and relevant statistical tests. The statistical analysis was carried out using the Statistical Package for Social Sciences for Windows (version 16.0). Descriptive statistics (mean and standard deviation) were used to describe the anthropometric variables. Chi-square analysis was done to assess the differences in the prevalence of stunting and thinness among the girls with the values reported from other Indian populations. The differences were considered to be statistically significant at $p<0.05$.

All necessary permissions were obtained from the school authorities prior to data collection. An informed consent was also taken from either parent of the girls. The study was conducted in accordance with the ethical guidelines of human experiments as laid down in the Helsinki Declaration of $2000^{39}$.

\section{Results}

Based on the socio-economic scale of Kuppuswamy ${ }^{36}$, it was observed that all the Rajbanshi adolescent girls belonged to a lower to middle SES. The age-specific descriptive statistics of the anthropometric variables among the girls are depicted in Table 1. The mean height and weight increased with age, except those aged 17 years (in height) and 16 years (in weight). The age-specific mean BMI was increased with age especially early age groups (e.g., 9-13 years), except those aged 14 years, 16 years and 18 years. The highest height and weight attainment was observed among girls aged 18 years. The mean age-specific mean BMI ranged from $14.01 \mathrm{~kg} / \mathrm{m}^{2}$ (in 9 years) to $20.05 \mathrm{~kg} / \mathrm{m}^{2}$ (in 17 years). The comparison of age-specific mean height and BMI values with the WHO (2007) reference showed that these adolescent girls were below the $50^{\text {th }}$ percentile values of reference and the differences were observed to be markedly different with the advancement of age. The age-specific mean height and BMI values were documented to be below the $5^{\text {th }}$ percentile and 25th percentile among the age groups of 16-18 years and 9-11 years, respectively (Fig. 1).

Prevalence of stunting and thinness: The overall prevalence of stunting and thinness was observed to be $39.60 \%$ and $26.00 \%$ respectively (Fig. 2). Prevalence of age-specific stunting was higher and lower among girls aged 17 years (70.21\%) and 10 years (24.00\%), respectively. The prevalence of stunting gradually increased as the girls approached higher ages (i.e., 16-18 years). The age-specific prevalence of thinness (low BMl-for-age) was observed to be higher among those belonging to early age groups (e.g., 9-11 years) and lower in higher age groups (e.g., 16-18 years). The age-specific prevalence of thinness was observed to be higher among girls aged 10 years (66.00\%) and lower among age 17 years (8.51\%) (Fig. 2). 


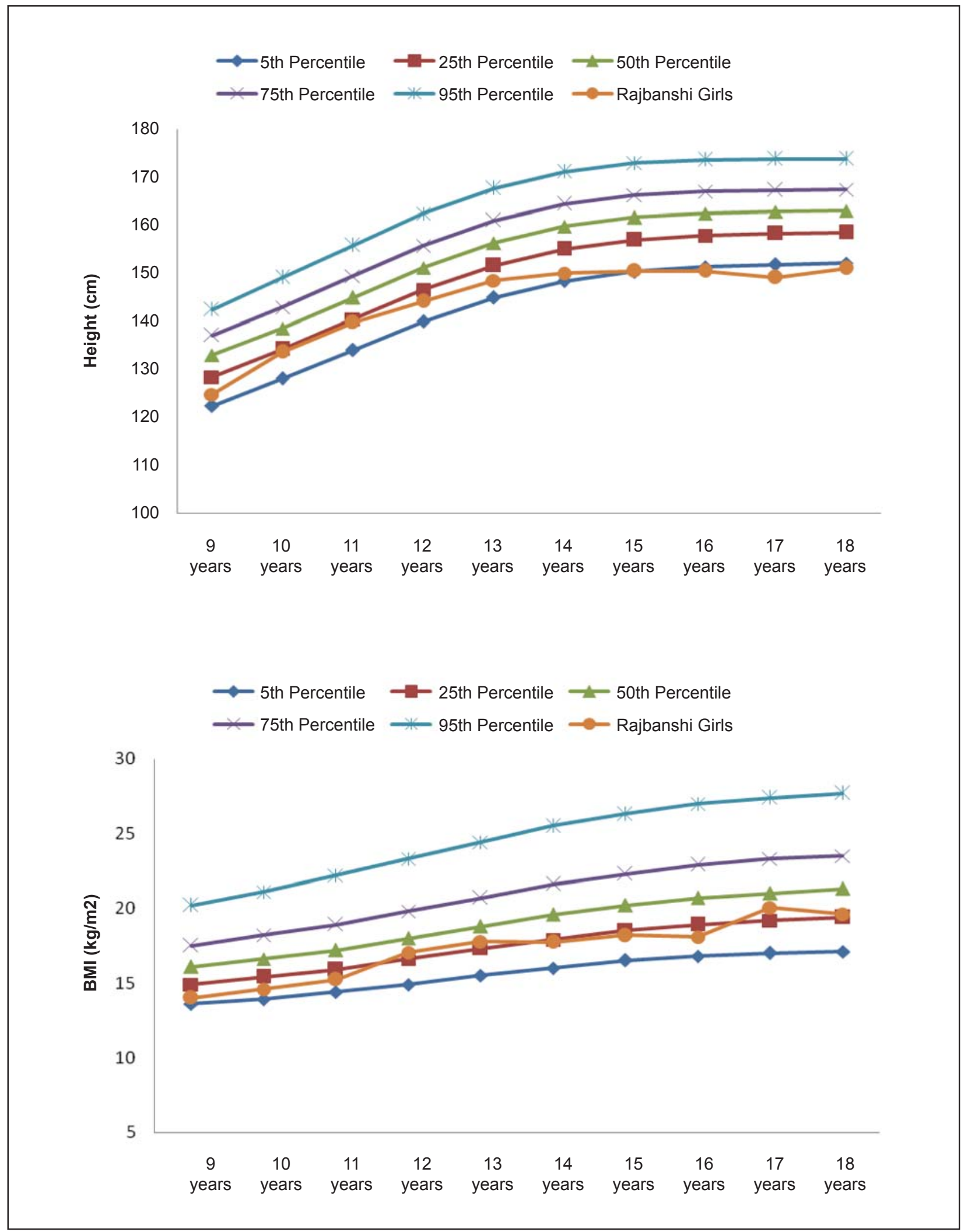

Fig 1: Age-specific mean comparison of height and BMI of the Rajbanshi adolescent girls with the $\mathrm{WHO}^{16}$ reference population 


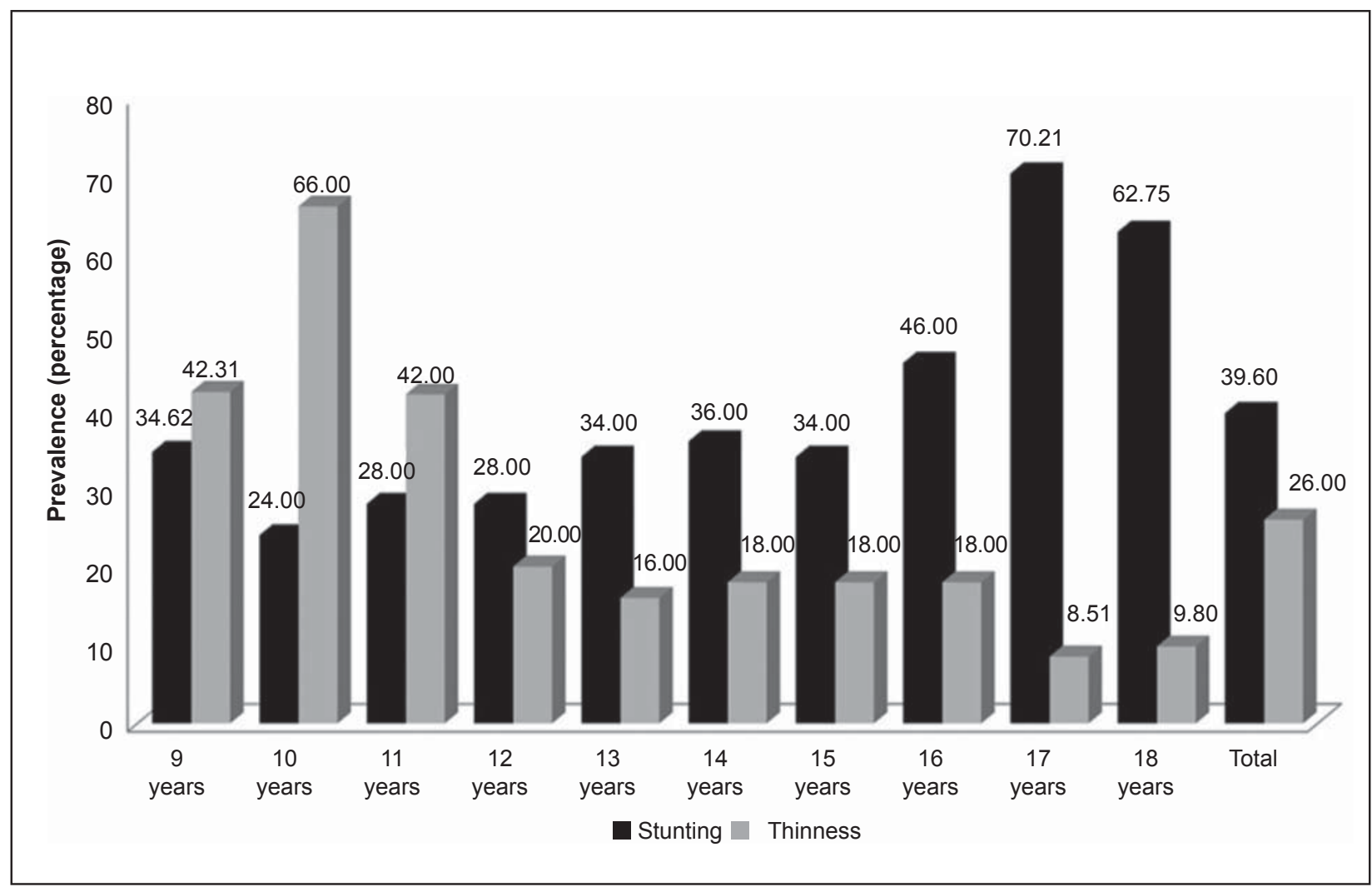

Fig 2: Age-specific prevalence of stunting and thinness among the Rajbanshi adolescent girls

Table 1: Age-specific subject distribution, descriptive statistics among the Rajbanshi adolescent girls

\begin{tabular}{ccccc}
\hline Age (years) & Number of girls & Height $\mathbf{( c m})$ & Weight $\mathbf{( k g )}$ & $\mathbf{B M I}\left(\mathbf{k g} / \mathbf{m}^{2}\right)$ \\
\hline 9 & 52 & $124.76 \pm 6.15$ & $21.82 \pm 2.82$ & $14.01 \pm 1.48$ \\
\hline 10 & 50 & $133.65 \pm 7.41$ & $26.43 \pm 7.57$ & $14.58 \pm 2.82$ \\
\hline 11 & 50 & $139.83 \pm 7.36$ & $29.90 \pm 5.76$ & $15.24 \pm 2.37$ \\
\hline 12 & 50 & $144.21 \pm 5.94$ & $35.59 \pm 7.12$ & $17.05 \pm 3.04$ \\
\hline 13 & 50 & $148.50 \pm 6.83$ & $39.31 \pm 6.61$ & $17.77 \pm 2.42$ \\
\hline 14 & 50 & $150.10 \pm 5.81$ & $40.16 \pm 6.85$ & $17.73 \pm 2.30$ \\
\hline 16 & 50 & $150.56 \pm 4.88$ & $41.30 \pm 6.50$ & $18.19 \pm 2.60$ \\
\hline 17 & 50 & $150.58 \pm 5.46$ & $41.10 \pm 5.58$ & $18.09 \pm 1.99$ \\
\hline 18 & 47 & $149.21 \pm 6.06$ & $44.63 \pm 7.11$ & $20.05 \pm 3.17$ \\
\hline Total & 51 & $151.08 \pm 6.17$ & $44.98 \pm 7.61$ & $19.61 \pm 2.36$ \\
\hline
\end{tabular}

Values are in parenthesis indicates percentage 
Table 2: Comparison of prevalence of stunting in the present study with the available published data

\begin{tabular}{|c|c|c|c|c|c|}
\hline Population/ Study Area & $\mathbf{N}$ & Stunting & $\mathrm{x}^{2}$ value & $p$-value & Reference \\
\hline Adolescent girls, North India & 156 & $64(41.00)$ & 0.043 & 0.83 & Anand et al. (40) \\
\hline Rural adolescent, India & 12124 & $4728(39.00)$ & 0.032 & 0.85 & Venkaiah et al. (5) \\
\hline $\begin{array}{l}\text { Adolescent girls, North } 24 \text { Pargana, West } \\
\text { Bengal }\end{array}$ & 143 & $54(37.80)$ & 0.069 & 0.79 & Das and Biswas (17) \\
\hline $\begin{array}{l}\text { Rural adolescent, Hooghly district, West } \\
\text { Bengal }\end{array}$ & 122 & $62(52.46)$ & 1.989 & 0.15 & Das et al. (19) \\
\hline Adolescents girls, North India & 209 & $62(29.70)$ & 2.995 & 0.08 & Malhotra and Passi (18) \\
\hline Tea garden children, Assam & 314 & $163(51.90)$ & 4.486 & 0.03 & Medhi et al. (8) \\
\hline Bengalee adolescent, Bankura, West Bengal & 253 & $49(19.40)$ & 16.708 & 0.00 & Bose et al. (22) \\
\hline $\begin{array}{l}\text { Adolescent girls, Urban slum area, South } \\
\text { India }\end{array}$ & 223 & $105(47.00)$ & 0.801 & 0.37 & Prashant and Shaw (23) \\
\hline Rural adolescents, Darjeeling, West Bengal & 350 & $176(50.30)$ & 3.667 & 0.05 & Mondol and Sen (10) \\
\hline $\begin{array}{l}\text { Adolescent girls, Paschim Mednipur, West } \\
\text { Bengal }\end{array}$ & 801 & $274(34.20)$ & 1.795 & 0.18 & Maiti et al. (44) \\
\hline Rural adolescent, South India & 230 & $74(32.17)$ & 1.734 & 0.18 & $\begin{array}{l}\text { Shivaramakrishna et al. } \\
\qquad(45)\end{array}$ \\
\hline Tripuri girls, Jampuijala, Tripura & 302 & $56(18.50)$ & 20.973 & 0.00 & Sil et al. (46) \\
\hline Rural adolescent, Tamil Nadu & 245 & $47(19.20)$ & 16.646 & 0.00 & Kumar (25) \\
\hline Adolescent girls, Karnataka India & 422 & $191(45.20)$ & 1.219 & 0.26 & $\begin{array}{l}\text { Rajaretnam and Hallad } \\
\text { (47) }\end{array}$ \\
\hline Tribal adolescents, West Bengal & 277 & $140(50.50)$ & 3.350 & 0.06 & Maiti et al. (24) \\
\hline Karbi adolescents, Karbi Anglong, Assam & 416 & $213(51.20)$ & 4.675 & 0.03 & Mondal and Terangpi (29) \\
\hline Rajbanshi Adolescents, West Bengal & 500 & $198(39.60)$ & - & - & Present study \\
\hline
\end{tabular}

Values in parenthesis indicate percentage

Table 3: Comparison of prevalence of thinness in the present study with the available published data

\begin{tabular}{lccccc}
\hline Population/ Study area & N & Thinness & X ${ }^{2}$ value & p-value & Reference \\
\hline Adolescent girls, North India & 156 & $47(30.10)$ & 0.582 & 0.44 & Anand et al. (40) \\
\hline Rural adolescent, India & 12124 & $4789(39.50)$ & 17.757 & 0.00 & Venkaiah et al. (5) \\
\hline Adolescent girls, West Bengal & 143 & $21(14.70)$ & 5.18 & 0.02 & Das and Biswas (17) \\
\hline Rural adolescent, Wardha, India & 344 & $20(69.80)$ & 41.273 & 0.00 & Deshmukh et al. (6) \\
\hline Rural adolescent, West Bengal & 122 & $22(18.03)$ & 2.131 & 0.14 & Das et al. (19) \\
\hline Adolescents girls, North India & 209 & $64(30.60)$ & 0.89 & 0.34 & Malhotra and Passi (18) \\
\hline Tea garden children, Assam & 314 & $131(41.32)$ & 10.993 & 0.00 & Medhi et al. (8) \\
\hline Rural adolescent, West Bengal India & 429 & $108(25.20)$ & 0.049 & 0.82 & Bose and Bisai (21) \\
\hline Adolescent girls, Urban slum area, South India & 223 & $46(20.60)$ & 1.496 & 0.22 & Prashant and Shaw (23) \\
\hline Rural adolescent, Darjeeling, West Bengal & 350 & $112(32.00)$ & 2.011 & 0.15 & Mondal and Sen (10) \\
\hline Adolescent, Paschim Mednipur, West Bengal & 801 & $302(37.70)$ & 9.748 & 0.00 & Maiti et al. (44) \\
\hline Tripuri girls, jampuijala, Tripura & 302 & $86(28.50)$ & 0.336 & 0.56 & Sil et al. (46) \\
\hline Rural Adolescent girls, Tamil Nadu & 245 & $69(28.20)$ & 0.226 & 0.63 & Kumar (25) \\
\hline Adolescent girls, Andhra Pradesh & 420 & $237(56.40)$ & 37.603 & 0.00 & Wasnik et al. (26) \\
\hline Tribal adolescents, West Bengal & 277 & $125(45.10)$ & 14.432 & 0.00 & Maiti et al. (24) \\
\hline Kurmi Adolescent girls, Raipur, Chhattisgarh & 500 & $291(58.30)$ & 43.892 & 0.00 & Patanwar and Sharma \\
\hline Rajbanshi Adolescents, West Bengal & 500 & $130(26.00)$ & - & - & Present study \\
\hline Values in parenty
\end{tabular}

Values in parenthesis indicate percentage 


\section{Discussion}

The World Health Organization (WHO) believes that the ultimate objective of the nutritional assessment is to improve human health and assess the health conditions by implementing specific nutritional intervention programs ${ }^{4}$. Undernutrition continues to be a major public health issue and a principal cause of ill-health condition $^{1,6}$. The assessment of undernutrition bears great significance in India; where a significant proportion of the population is suffering from different grades of undernutrition ${ }^{1-3,7,9,10,31}$. The prevalence of stunting was significantly higher in the higher age groups (i.e., 16-18 years) (Fig.2). Several studies have reported that the prevalence was found to be significantly higher among adolescents in age groups $8,10,29$. A number of studies have reported the prevalence of stunting as a major nutritional problem among adolescents in India (Table 2). A high prevalence of stunting has been documented from Assam $(51.90 \%)^{8}$, West Bengal $(52.46 \%)^{19}$,Wardha $(50.70 \%)^{6}$, North Indian $(37.20 \%)^{40}$ and Karbi Anglong, Assam $(51.20 \%)^{29}$. The National Nutrition Monitoring Bureau (NNMB) data showed that approximately $39.00 \%$ of adolescents from the rural areas were stunted ${ }^{9}$. A relatively very high prevalence of stunting ( $\geq 40.00 \%$ ) was reported for Indian adolescents, $8,19,24,26,27,29$ (Table 3 ). The main reason behind stunting indicates the longterm cumulative inadequacies of health and nutrition and an insufficient intake of nutrients during the early stage of childhood among adolescents ${ }^{6,8,10}$.

The present study has utilized low BMI-for-age as an indicator of thinness. The prevalence of thinness was significantly higher in the early age groups in most of the cases (e.g., 9-11 years), but decreased with age (Fig. 2). A similar trend has been reported that the prevalence of thinness decreased with age $1,8,10,29,41$. Several researchers have reported a higher prevalence

\section{References}

1. Nandy S, Irving M, Gordon D, Subramanian SV, Smith GD. Poverty, child undernutrition and morbidity: New evidence from India. Bull World Health Organ 2005;83:210-6.

2. Kapil U, Sachdev HP. Urgent need to orient public health response to rapid nutrition transition. Indian J Community Med 2012;37:207-10.

3. Varadharajan KS, Thomas T, Kurpad AV. Poverty and the state of nutrition in India. Asia Pac J Clin Nutr 2013;22:326-39.

4. World Health Organization. Physical Status. The Use and Interpretation of Anthropometry. Technical of thinness among the Indian adolescents from Indian $(39.50 \%)^{5}$, North Indian $(30.10 \%)^{40}$, Assam $(41.32)^{8}$, Chhattisgarh $(58.30 \%)^{27}$, Indian tribes $(42.00 \%)^{42}$, Andhra Pradesh $(56.40 \%)^{26}$ and West Bengal $(32.00 \%)^{10}$. It is now generally accepted that there is a high prevalence of thinness among Indian communities with more than $40.00 \%$ of the adolescents being affected ${ }^{6,8,24,26,27}$ (Table 3). The prevalence of undernutrition during childhood and adolescence have not only delayed growth attainment but affected overall the linear mechanism of growth processes ${ }^{4,7}$. Those adolescents suffering from thinness are more likely to develop into thin adults with a lower BMI or $\mathrm{CED}^{4}$ that would have an impact on reducing the physical work productivity as well as lead to greater morbidity and mortality in the population. Prevalence of thinness is frequently associated with nutritional deficiencies, menstrual irregularity and adverse reproductive outcomes among adolescent girls and young women ${ }^{4,28,30}$.

\section{Conclusion}

The results of the present study have reported a high prevalence of stunting and thinness among adolescents belonging to the indigenous Rajbanshi population of North Bengal. There is an urgent need of appropriate nutritional intervention program to address the public health problem related to undernutrition especially among nutritionally vulnerable segments of adolescents residing in rural regions to ameliorate the nutritional status. The results of the present study would also help to reveal the enhanced usefulness and effectiveness of the launched and/or ongoing intervention or supplementary programs at targeted populations. Further studies with the interdisciplinary approach and comprehensive methods are required to explore dietary pattern, nutrient intake, disease prevalence and their association with undernutrition status among adolescents.
Report Series No. 854. Geneva: World Health Organization, 1995.

5. Venkaiah K, Damayanti K, Nayak MU, Vijayaraghavan $\mathrm{K}$. Diet and nutritional status of rural adolescents in India. Eur J ClinNutr 2002;56:1119-25.

6. Deshmukh PR, Gupta SS, Bharambe MS, Dongre AR, Maliye C, Kaur S, Garg BS. Nutritional status of adolescents in rural Wardha. Indian $\mathrm{J}$ Pediatr 2006;73:139-41.

7. Parasuraman S, Kishor S, Singh SK, Vaidehi Y. A Profile of Youth in India. National Family Health Survey (NFHS-3), India, 2005-06. Mumbai: International Institute for Population Sciences; Calverton, Maryland, USA: ICF Macro, 2009. 
8. Medhi GK, Hazarika NC, Mahanta J. Nutritional status of adolescents among tea garden workers. Indian J Pediatr 2007;74:343-7.

9. Mondal N, Sen J. Prevalence of undernutrition among children (5-12 years) belonging to three communities residing in a similar habitat in North Bengal, India. Ann Hum Biol 2010;37:198- 216.

10. Mondal N, Sen J. Prevalence of stunting and thinness among rural adolescents of Darjeeling district, West Bengal, India. Italian J Pub Health 2010;7:54-61.

11. Bose K, Bhattacharya S, Basu K, Ghosh S, Mukhopadhyay A, Bhadra M. Age trends in anthropometric characteristics among 6-9 years old Bengalee Hindu school girls of Kolkata, India. Anthropol Anz 2005;63:439-48.

12. Bisai S, Bose K. Undernutrition in the Kora Mudi tribal population, West Bengal, India: a comparison of body mass index and mid-upper-arm circumference. Food Nutr Bull 2009;30:63-7.

13. Das $\mathrm{S}$, Bose K. Nutritional assessment by mid-upper arm circumference of santal adults of Purulia, West Bengal, India. Coll Antropol 2012;36:581-4.

14. Ferreira AA, Welch JR, Santos RV, Gugelmin SA, Coimbra CE Jr. Nutritional status and growth of indigenous Xavante children, Central Brazil. Nutr J 2012;11:3.

15. Aguayo VM, Aneja S, Badgaiyan N, Singh K. Mid upper-arm circumference is an effective tool to identify infants and young children with severe acute malnutrition in India. Public Health Nutr 2015;18:3244-8.

16. World Health Organization child growth standards: head circumference for-age, arm circumferenceforage, triceps skinfold-for-age and subscapular skinfold-for-age: methods and development. Geneva, World Health Organization, 2007.

17. Das DK, Biswas R. Nutritional status of adolescent girls in a rural area of North 24 Parganas district, West Bengal. Indian J Public Health 2005;49:18-21.

18. Malhotra A, Passi SJ. Diet quality and nutritional status of rural adolescent girl beneficiaries of ICDS in north India. Asia Pac J Clin Nutr 2007;16:8-16.

19. Das P, Ray SK, Joardar GK, Dasgupta S. Nutritional profiles of adolescents in a rural community of Hooghly district in West Bengal. Indian J Public Health 2007;51:120-1.

20. Bisai S, Bose K, Ghosh A. Nutritional status of Lodha children in a village of Paschim Medinipur district, West Bengal. Indian J Public Health 2008;52:203-6.

21. Bose K, Bisai S. Prevalence of undernutrition among rural adolescents of West Bengal, India. J Trop Pediatr 2008;54:422-423.
22. Bose K, Bisai S, Mukherjee S. 2008. Anthropometric characteristics and nutritional status of rural school children. Intern J Biol Anthropol 2:1.

23. Prashant $\mathrm{K}$, Shaw $\mathrm{C}$. Nutritional status of adolescent girls from an urban slum area in South India. Indian $J$ Pediatr 2009;76:501-4.

24. Maiti S, Ghosh D, Paul S. Determinants of Nutritional Status among Tribal Adolescent in Girls Paschim Medinipur District of West Bengal. Int J Prev Med 2012;3:298-9.

25. Kumar TA. Nutritional Status of Adolescent Girls in Rural Tamilnadu. Nat J Res Com Med 2012:1:48-51

26. Wasnik V, Rao BS, Rao D. A Study of the Health Status of Early adolescent Girls residing in Social Welfare Hostels in Vizianagaram district of Andhra Pradesh State, India. Int J Collaborative Res Internal Med Public Health 2012;4:72-83.

27. Patanwar P, Sharma KKN. Nutritional Status of Kurmi Adolescent Girls of Raipur City Chhattisgarh, India. Int J Scientific Res Pub 2013;3:1-6.

28. Mondal N. Thinness as Major Underlying Problem among Adolescents of Northeast India. J Nepal Paediatr Soc 2014;34:39-47.

29. Mondal N, Terangpi M. 2014. Prevalence of undernutrition among tribal adolescents of Karbi Anglong district of Assam, Northeast India. Sri Lanka J Child Health 2014;43:154-7.

30. Sen J, Roy A, Mondal N. Association of maternal nutritional status, body composition and socioeconomic variables with low birth weight in India. $J$ Trop Pediatr 2010; 56:254-9.

31. Sen J, Mondal N. Socio-economic and demographic factors affecting the Composite Index of Anthropometric Failure (CIAF). Ann Hum Biol 2012;39:129-36.

32. Datta Banik S. Body mass index and blood pressure among men of three ethnic groups of Darjeeling, West Bengal, India. Ecol Food Nutr 2014;53:256-72.

33. Mittal PC, Srivastava S. Diet, nutritional status and food related traditions of Oraon tribes of New Mal (West Bengal), India. Rural Remote Health 2006;6:385.

34. Tigga PL, Sen J, Mondal N. Association of some socio-economic and socio-demographic variables with wasting among pre-school children of North Bengal, India. Ethiop J Health Sci 2015;25:63-72.

35. Mukhopadhyay DK, Biswas R, Chakraborty M, Sadhukhan SK, Banik KK. Anthropometric failure, a new approach to measure undernutrition: an experience from a rural community of West Bengal, India. J Indian Med Assoc 2009;107:211-14.

36. Mishra D, Singh HP. Kuppuswami's socio-economic status scale- A revision. Indian J Pediatr 2003;70:2734. 
37. Hall JG, Allanson JE, Gripp KW, Slavotinek AM. Handbook of Physical Measurements. New York: Oxford University Press; 2007.

38. Ulijaszek SJ, Kerr DA. Anthropometric measurement error and the assessment of nutritional status. Brit $J$ Nutr 1999;82:165-77.

39. Touitou Y, Portaluppi F, Smolensky MH, Rensing L. Ethical principles and standards for the conductof human and animal biological rhythm research. Chronobiol Int 2004; 21:161-70.

40. Anand K, Kant S, Kapoor SK. Nutritional status of adolescent school children in rural North India. Indian Pediatr 1999;36:810-15.

41. Shahabuddin AK, Talukder K, Talukder MK, Hassan M, Seal A, Rahman $Q$, Mannan A, Tomkins A, Costello $A$. Adolescent nutrition in a rural community in Bangladesh. Indian J Pediatr 2000;67:93-8.

42. Rao KM, Laxmaiah A, Venkaiah K, Brahmam GN. Diet and nutritional status of adolescent tribal population in nine states of India. Asia Pac J Clin Nutr 2006;15:64-71.

43. Tiwari MK, Sharma KK, Bharati S, Adak DK, Ghosh $R$, Bharati $P$. Growth and nutritional status of the Bharia - a primitive tribe of Madhya Pradesh. Coll Antropol 2007;31:95-101.

44. Maiti S, De D, Chatterjee K, Jana K, Ghosh D, Paul $S$. Prevalence of stunting and thinness among early adolescent school girls of Paschim Medinipur district, West Bengal. Int J Biol Med Res 2011;2:781-3.

45. Shivaramakrishna HR, Deepa AV, Sarithareddy M. Nutritional Status of Adolescent Girls in Rural Area of Kolar District -A Cross-Sectional Study. Al Ame J Med Sci 2011;4:243-6.

46. Sil SK, Sarkar SR, Saha S, Roy S. Assessment of nutritional status of rural tribal children in Tripura. Indian Pediatr 2011;48:488-9.

47. Rajaretnam T, Hallad JS. Nutritional status of adolescents in northern Karnataka, India. J Family Welfare 2012;58:55-67. 